\title{
Efficacy of Antiemetic Regimens for Prevention and Treatment of Chemotherapy-Induced Nausea and Vomiting in Patients of Breast Cancer Receiving Highly Emetogenic Chemotherapy
}

\begin{abstract}
Background: Chemotherapy is fraught with serious and troublesome adverse effects, of which nausea and vomiting appears earliest and is the most disturbing. Therefore, this study was planned to investigate the antiemetic drug regimens used for chemotherapy-induced nausea vomiting (CINV) in patients with breast cancer receiving highly emetogenic chemotherapy (HEC). Subjects and Methods: An observational follow-up study was conducted to assess the efficacy of antiemetic regimens in breast cancer patients receiving HEC. A total of 71 newly diagnosed patients with breast cancer were included in the study. Patients were assessed for nausea by the visual analog scale, and a history of emetic episodes and need for rescue medication were recorded at $0 \mathrm{~h}, 6 \mathrm{~h}$, $24 \mathrm{~h}, 48 \mathrm{~h}$, and $120 \mathrm{~h}$ post-chemotherapy till three cycles. Results: The patients were prescribed a combination of ondansetron and dexamethasone $(n=23, n=17$, and $n=13$ in first, second, and third cycle, respectively) or a combination of aprepitant, ondansetron, and dexamethasone $(n=48$, $n=54$ and $n=56$ in the first, second, and third cycle, respectively). The intensity of nausea was higher for the patients who were prescribed ondansetron and dexamethasone regimen as compared to patients prescribed aprepitant additionally. Complete response, i.e., no emesis and no rescue medication, was higher in triple-drug regimen (52\% vs. $0.4 \%, 63 \%$ vs. $17.6 \%$, and $69 \%$ vs. $23 \%$ in three cycles, respectively). Conclusion: The control of CINV was better with a combination of aprepitant, ondansetron, and dexamethasone as compared to a regimen without aprepitant.
\end{abstract}

Keywords: 5-HT3 receptor antagonist, breast cancer, chemotherapy-induced nausea and vomiting, highly emetogenic chemotherapy, NK-1 receptor antagonist

\section{Introduction}

Cancer as a noncommunicable disease presents a tremendous burden on patients, their caregivers, and society. The currently estimated burden of cancer worldwide is touching to 18 million in 2018 and is going to reach up to 29.5 million by 2040 , with the leading causes being tumors of the lung, breast, and prostate. ${ }^{[1]}$

In India, an estimated 1.15 million patients were diagnosed with cancer in the year 2018 . The leading causes of cancer in males are cancers of the oral cavity and lip, followed by lung and stomach cancer. In females, the most common cancer site affected is the breast, followed by the oral cavity and lip and the cervix. An estimated 14\% of all newly diagnosed cancer cases are of breast tumors. ${ }^{[2]}$

For the treatment of breast cancer, the mainstay of treatment is surgery to remove

\footnotetext{
This is an open access journal, and articles are distributed under the terms of the Creative Commons Attribution-NonCommercial-ShareAlike 4.0 License, which allows others to remix, tweak, and build upon the work non-commercially, as long as appropriate credit is given and the new creations are licensed under the identical terms.
}

For reprints contact: WKHLRPMedknow_reprints@wolterskluwer.com the tumor, followed by chemotherapy, radiotherapy, and hormonal therapy, depending on the tumor type and stage. The chemotherapy commonly prescribed to these patients is a combination of anthracycline-cyclophosphamide.

However, chemotherapy is fraught with a high frequency of serious and troublesome adverse effects that compromise not only the quality of life of the patient but also the patient compliance with the treatment. One of the most common and troublesome adverse effects is associated with nausea and vomiting, which appears earliest, and has a profound impact on the quality of life of the patient. ${ }^{[3]}$

Chemotherapy-induced nausea and vomiting (CINV) can be labeled as acute (within $24 \mathrm{~h}$ ), delayed (beyond $24 \mathrm{~h}$ ), anticipatory, breakthrough, and refractory, may present in all permutations and

How to cite this article: $\mathrm{Vij} \mathrm{S}$, Dhasmana DC, Bala S, Verma SK. Efficacy of antiemetic regimens for prevention and treatment of chemotherapy-induced nausea and vomiting in patients of breast cancer receiving highly emetogenic chemotherapy. Indian J Med Paediatr Oncol 2020;41:819-24.

\section{Soumya $\mathrm{Vij}^{1}$, Dilip Chander Dhasmana ${ }^{1}$, Suman Bala ${ }^{1}$, Sanjiv Kumar Verma $^{2}$}

${ }^{1}$ Department of Pharmacology, Himalayan Institute of Medical Sciences,

Swami Rama Himalayan

University, Dehradun,

Uttarakhand, India, ${ }^{2}$ Department of Medicine, Himalayan Institute of Medical Sciences,

Swami Rama Himalayan

University, Dehradun,

Uttarakhand, India

Submitted: 27-Apr-2020

Revised: 09-Aug-2020

Accepted: $22-$ Aug-2020

Published: 31-Dec-2020

\section{Address for correspondence:}

Dr. Dilip Chander Dhasmana,

Department of Pharmacology,

Himalayan Institute of

Medical Sciences, Swami

Rama Himalayan University,

Dehradun, Uttarakhand, India.

E-mail: dhasmanadc@gmail. com

Access this article online

Website: www.ijmpo.org

DOI: 10.4103/ijmpo.ijmpo_200_20 Quick Response Code:

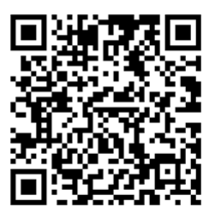


combinations, that are substantially challenging for the physician as well as to the patient. ${ }^{[4]}$ Each chemotherapeutic agent used varies in its ability to induce emesis, with some drugs such as cisplatin, cyclophosphamide (dose $>1500 \mathrm{mg} / \mathrm{m}^{2}$ ) and anthracycline- cyclophosphamide combinations being implicated as highly emetogenic and induce emesis in up to $90 \%$ of the patients receiving the drugs. ${ }^{[5]}$

It is imperative that nausea and vomiting occurring due to chemotherapy must be prevented and treated optimally. For the prophylaxis of CINV, the drugs primarily included are NK-1 receptor antagonists, such as aprepitant and fosaprepitant and 5HT3 receptor antagonists such as ondansetron, granisetron and palonosetron, and dexamethasone. ${ }^{[6]}$ Apart from this, other drugs used are olanzapine, metoclopramide, domperidone, etc. ${ }^{[7]}$

There is a dearth of data on the efficacy of the treatment of CINV from the Indian subcontinent. There are no standard guidelines present from this region to suggest the appropriate drug therapy for the prevention and treatment of CINV.

Thus, the present study was undertaken to observe the antiemetics prescribed to prevent and treat CINV and their efficacy for patients with breast cancer planned to receive highly emetogenic chemotherapy (HEC).

\section{Subjects and Methods}

The study was conducted over a period of 12 months in the Day Care Ward of the Cancer Research Institute after obtaining written informed consent. The study was conducted in accordance with the principles of the Declaration of Helsinki and after obtaining clearance from the institutional ethics committee. A total of 71 patients diagnosed with breast cancer were included in the study and were followed up until the third cycle of chemotherapy.

Previously untreated patients (chemotherapy-naïve) female patients in the age group 18-65 years, newly diagnosed with breast cancer, post-surgery for tumor removal, and planned to receive HEC were included in the study after obtaining written informed consent.

Any patients planned to receive concurrent radiotherapy, patients with metastatic tumors, patients with a history of previous exposure to chemotherapy, and pregnant or lactating females were excluded from the study.

Demographic details including the age, weight, height, body mass index, and body surface area were recorded in case recording forms and any relevant medical and personal history was collected from the patients as well as caretakers. This included a history of motion sickness and morning sickness. The patients were prescribed antiemetic regimens as per the physician's preference and could be modified in subsequent cycles depending upon the experience of the patient.
The intensity of nausea was assessed based on a 10-point visual analog scale (VAS). 0 in the VAS corresponded to no nausea at all and 10 in the VAS corresponded to the worst possible nausea. The VAS responses were recorded at $0 \mathrm{~h}, 6 \mathrm{~h}, 24 \mathrm{~h}, 48 \mathrm{~h}$, and $120 \mathrm{~h}$ postchemotherapy.

The patients were given an Emesis Diary and were instructed on how to fill the diary. The patients were instructed to record the frequency of vomiting episodes and any need for rescue medications. The frequency of vomiting episodes and the need for rescue medication were analyzed in the acute and delayed phase, as well as the overall phase for the different antiemetic regimens given to the patients.

A detailed analysis of the antiemetic drugs prescribed was done based on feedback given by the patient. Patients were similarly assessed at subsequent cycles, till three cycles of chemotherapy.

\section{Data management and statistical analysis}

All of the data from the case recording forms and questionnaire were entered in a master chart on Microsoft Excel for the analysis. The statistical analysis was based on standard descriptive statistical tests using Microsoft Excel and Statistical Package for the Social Sciences version 20.0 (SPSS, Inc.; Chicago, IL, USA) for Windows. The demographic data and VAS scores were represented as mean \pm standard deviation and a history of morning and motion sickness was depicted in terms of frequency. The efficacy of the antiemetic regimes was assessed by comparison of the mean scores of VAS by the independent $t$-test. The chemotherapy regimens prescribed along with the antiemetic regimen used are depicted in frequency and percentage. The vomiting frequency, need for rescue medication, and complete response were expressed in frequency and percentages.

\section{Results}

Seventy-one patients recently diagnosed with Carcinoma Breast who received adjuvant HEC were included in the study. All of these patients had undergone surgical tumor removal before starting chemotherapy. All of these patients had been prescribed chemotherapy, followed by hormone therapy and radiotherapy. Sixty-seven patients (94\%) had been diagnosed with infiltrating ductal carcinoma of the breast. The mean age of the patients included in the study was $51.49 \pm 10.81$ years. The minimum age was 27 years and the maximum age was 65 years. Forty-one patients reported a positive history of morning sickness and 35 patients gave a positive history of motion sickness [Table 1].

Of the 71 patients analyzed, 21 patients received a combination of Adriamycin and cyclophosphamide and 50 patients received epirubicin along with cyclophosphamide [Table 2].

All patients $(n=71)$ were prescribed premedication in with at combination of ondansetron and dexamethasone 
intravenously at a dose of $8 \mathrm{mg}$ each or a dose of $16 \mathrm{mg}$ each. Along with this, in the first cycle, 48 patients were prescribed an aprepitant kit, given as $125 \mathrm{mg}$ orally on the $1^{\text {st }}$ day of chemotherapy and followed by a maintenance dose of $80 \mathrm{mg}$ orally on days 2 and 3. The antiemetic regimens prescribed were as per the treating physician's discretion and were modified in subsequent cycles based on the feedback given by the patient as per her experience in the prior cycle. Thus, six patients in the second cycle were escalated to a regimen containing aprepitant and four more in the third cycle were prescribed additional aprepitant [Table 3]. In all cycles, the patients were given ondansetron three times a day for 5 days, as well as rescue medication in case the patient experienced more nausea or increased frequency of vomiting episodes. In case of severe nausea or vomiting, patients were prescribed injection granisetron $3 \mathrm{mg}$ intravenously.

None of the patients in the first cycle required rescue with injection granisetron. Two patients in the second cycle and one patient in the third cycle received granisetron as rescue medication.

The mean scores for the intensity of nausea as per the VAS were higher for the patients who were prescribed ondansetron and dexamethasone alone as compared to patients prescribed Aprepitant plus ondansetron and dexamethasone. The VAS scores were highly significant in the triple-drug regimen at $6 \mathrm{~h}, 24 \mathrm{~h}$, and $48 \mathrm{~h}$ postchemotherapy as compared to the two-drug regimen [Table 4a]. In the second cycle and third cycles, the mean VAS scores were significantly lower at $6 \mathrm{~h}, 24 \mathrm{~h}$, and $48 \mathrm{~h}$ postchemotherapy for the patients receiving aprepitant as part of the antiemetic regimen [Tables $4 \mathrm{~b}$ and $\mathrm{c}$ ].

In cycles 2 and 3, patients in both the regimens experienced nausea at $0 \mathrm{~h}$ of chemotherapy, i.e., anticipatory nausea; however, we did not observe a statistically significant difference in the extent of anticipatory nausea between the two regimens [Figure 1].

In the cycle 1 of chemotherapy, in the overall period $(0-120 \mathrm{~h})$, patients reporting with no episodes of vomiting were higher in patients receiving aprepitant in addition to ondansetron and dexamethasone as compared to patients who were not prescribed aprepitant $(52 \%$ in comparison to $0.4 \%$ ). Similarly, in the acute phase $(<24 \mathrm{~h}), 91.6 \%$ of the patients receiving a regimen of aprepitant along with ondansetron and dexamethasone reported no incidence of vomiting as compared to $47.8 \%$ of the patients in the

\begin{tabular}{lc}
$\begin{array}{c}\text { Table 1: Demographic profile and clinical characteristics } \\
\text { of patients with breast cancer receiving highly } \\
\text { emetogenic chemotherapy }(\boldsymbol{n}=\mathbf{7 1})\end{array}$ \\
\hline Criteria & Subjects $(\boldsymbol{n}=\mathbf{7 1})$ \\
\hline Age (years) & $51.49 \pm 10.81$ \\
Weight $(\mathrm{kg})$ & $63.28 \pm 11.22$ \\
Height $(\mathrm{cm})$ & $155.48 \pm 6.05$ \\
Body surface area $\left(\mathrm{m}^{2}\right)$ & $1.64 \pm 0.16$ \\
Body mass index $\left(\mathrm{kg} / \mathrm{m}^{2}\right)$ & $26.22 \pm 4.36$ \\
History of morning sickness & 41 \\
History of motion sickness & 35 \\
History of motion and morning sickness & 25 \\
\hline
\end{tabular}

Values expressed as mean \pm SD. SD: Standard deviation

Table 2: Highly emetogenic chemotherapy regimens prescribed in patients with breast cancer, along with mean doses prescribed $(n=71)$

\begin{tabular}{lclc}
\hline $\begin{array}{l}\text { Regimen } \\
\text { number }\end{array}$ & $\begin{array}{c}\text { Number } \\
\text { of patients }\end{array}$ & Regimen & Dose (mg) \\
\hline 1 & 50 & Epirubicin & $154.2 \pm 9.18$ \\
& & Cyclophosphamide & $925 \pm 136.5$ \\
2 & 21 & Adriamycin & $86.36 \pm 7.1$ \\
& & Cyclophosphamide & $872 \pm 82.2$ \\
\hline
\end{tabular}

Values are expressed in mean \pm SD. SD: Standard deviation

\begin{tabular}{|c|c|c|c|c|}
\hline \multirow[t]{2}{*}{ Cycle } & \multicolumn{2}{|c|}{$\begin{array}{c}\text { Ondansetron }+ \\
\text { dexamethasone }(\%)\end{array}$} & \multicolumn{2}{|c|}{$\begin{array}{c}\text { Aprepitant kit }+ \\
\text { ondansetron }+ \\
\text { dexamethasone }(\%)\end{array}$} \\
\hline & $8+8 \mathrm{mg}$ & $16+16 \mathrm{mg}$ & $8+8 \mathrm{mg}$ & $16+16 \mathrm{mg}$ \\
\hline Cycle 1 & 2 & 21 & 0 & 48 \\
\hline Cycle 2 & 2 & 15 & 0 & 54 \\
\hline Cycle 3 & 0 & 13 & 2 & 56 \\
\hline Total (213) & $4(2)$ & $49(23)$ & $2(1)$ & $158(74)$ \\
\hline
\end{tabular}

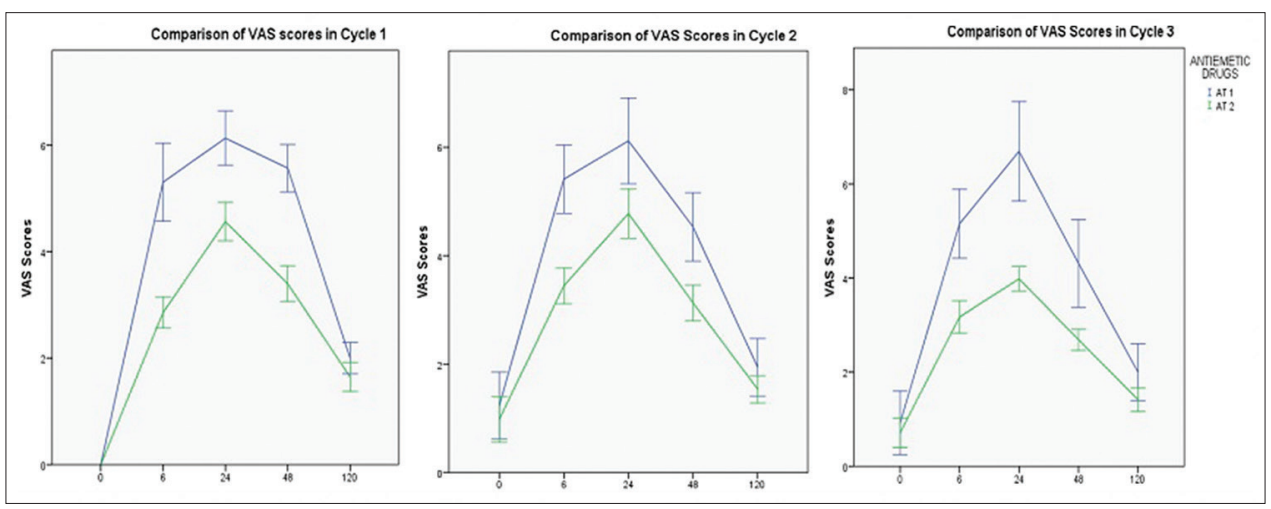

Figure 1: Visual analog scale scores for intensity of nausea in all cycles in patients receiving antiemetic regimens for highly emetogenic chemotherapy $(n=71)$ 
ondansetron and dexamethasone group. In the delayed phase $(>24 \mathrm{~h}), 54 \%$ of the patients said that they experienced no episode of vomiting when prescribed the aprepitant regimen, as compared to $13 \%$ of patients on ondansetron and dexamethasone regimen. Similar results were observed in the second and third cycles as well [Table 5].

Further, in our study, none of the patients prescribed either antiemetic regimen reported a complete control of symptoms, i.e., no nausea, no emesis, and no need for rescue medication across any of the cycles of chemotherapy.

In our study, five patients had adverse drug reactions which were possibly linked to the antiemetic regimens used.
Three patients reported urticaria after injection ondansetron and were prescribed antihistaminic drugs for the same. Two patients reported constipation, which likely could be due to ondansetron, and were treated with stool softeners. None of the patients reported any serious adverse effects linked to the antiemetic regimens.

\section{Discussion}

The impact of the diagnosis and treatment of cancer is not only on the physical domain of well-being but also on the emotional, social, and spiritual aspects of a person. ${ }^{[8]}$ Chemotherapy as such, by default, results in definite adverse effects as well as long-term sequelae such

Table 4a: Comparison of visual analog scale score for intensity of nausea in cycle 1 in patients receiving antiemetic regimens for highly emetogenic chemotherapy $(n=71)$

\begin{tabular}{|c|c|c|c|}
\hline Time (h) & Ondansetron + dexamethasone $(n=23)$ & Aprepitant + ondansetron + dexamethasone $(n=48)$ & $P$ \\
\hline At 0 & 0 & 0 & \\
\hline At 6 & $5.30 \pm 1.69$ & $2.85 \pm 1.01$ & 0.000 \\
\hline At 24 & $6.13 \pm 1.18$ & $4.56 \pm 1.24$ & 0.000 \\
\hline At 48 & $5.57 \pm 1.04$ & $3.40 \pm 1.16$ & 0.000 \\
\hline At 120 & $2 \pm 0.67$ & $1.65 \pm 0.93$ & 0.109 \\
\hline
\end{tabular}

Independent $t$-test. Values expressed as mean \pm SD. SD: Standard deviation

Table 4b: Comparison of visual analog scale score for intensity of nausea in cycle 2 in patients receiving antiemetic regimens for highly emetogenic chemotherapy $(n=71)$

\begin{tabular}{|c|c|c|c|}
\hline Time (h) & Ondansetron + dexamethasone $(n=17)$ & Aprepitant + ondansetron + dexamethasone $(n=54)$ & $\boldsymbol{P}$ \\
\hline At 0 & $1.24 \pm 1.20$ & $0.98 \pm 1.55$ & 0.538 \\
\hline At 6 & $5.41 \pm 1.23$ & $3.44 \pm 1.21$ & 0.000 \\
\hline At 24 & $6.12 \pm 1.54$ & $4.78 \pm 1.67$ & 0.004 \\
\hline At 48 & $4.53 \pm 1.23$ & $3.13 \pm 1.21$ & 0.000 \\
\hline At 120 & $1.94 \pm 1.03$ & $1.54 \pm 0.93$ & 0.131 \\
\hline
\end{tabular}

Independent $t$-test. Values expressed as mean $\pm \mathrm{SD}$. SD: Standard deviation

Table 4c: Comparison of visual analog scale score for intensity of nausea in cycle 3 in patients receiving antiemetic regimens for highly emetogenic chemotherapy $(n=71)$

\begin{tabular}{|c|c|c|c|}
\hline Time (h) & Ondansetron + dexamethasone $(n=13)$ & Aprepitant + ondansetron + dexamethasone $(n=58)$ & $\boldsymbol{P}$ \\
\hline At 0 & $0.92 \pm 1.12$ & $0.71 \pm 1.20$ & 0.554 \\
\hline At 6 & $5.15 \pm 1.21$ & $3.17 \pm 1.30$ & 0.000 \\
\hline At 24 & $6.69 \pm 1.75$ & $3.98 \pm 0.98$ & 0.000 \\
\hline At 48 & $4.31 \pm 1.55$ & $2.69 \pm 0.86$ & 0.003 \\
\hline At 120 & $2 \pm 1$ & $1.41 \pm 0.96$ & 0.05 \\
\hline
\end{tabular}

Independent $t$-test. Values expressed as mean \pm SD. SD: Standard deviation

Table 5: Comparison of frequency of no emesis in the acute, delayed, and overall phase in patients receiving antiemetic regimens for highly emetogenic chemotherapy $(n=71)$

\begin{tabular}{lcccc}
\hline Cycle & Regimen $(\boldsymbol{n})$ & Acute phase (<24 h) (\%) & Delayed phase (24- 120 h) (\%) & Overall phase (0- 120 h) (\%) \\
\hline Cycle 1 & At 1 (23) & $11(47.8)$ & $3(13)$ & $1(0.4)$ \\
& At 2 (48) & $44(91.6)$ & $26(54)$ & $25(52)$ \\
Cycle 2 & At 1 (17) & $11(64.7)$ & $3(17.6)$ & $3(17.6)$ \\
& At 2 (54) & $44(81.4)$ & $37(68.5)$ & $34(63)$ \\
Cycle 3 & At 1 (13) & $8(61.5)$ & $4(30.7)$ & $3(23)$ \\
& At 2 (58) & $53(91.3)$ & $46(79.3)$ & $40(69)$ \\
\hline
\end{tabular}

At 1: Ondansetron + dexamethasone, At 2: Aprepitant + ondansetron + dexamethasone 
as neutropenia, anemia, and bone marrow suppression along with gastrointestinal adverse effects like nausea and vomiting, mucositis, and diarrhea. ${ }^{[9]}$ All these adverse effects may translate to noncompliance to the treatment protocol or a higher cost of treatment to be paid by the patient. ${ }^{[10]}$

Nausea and vomiting is a very distressing side effect induced by chemotherapy for solid tumors which not only occurs very commonly in almost $70 \%-80 \%$ individuals but is also recurrent, that is, the patient will experience it during every subsequent cycle as well. ${ }^{[1]}$ This can lead to nonadherence to the chemotherapeutic treatment, which can affect disease progression and recurrence. Further, nausea and vomiting has severe effects on the quality of life with impaired functioning, increased anxiety, or depression. ${ }^{[3]}$

Despite the best efforts to optimize the use of antiemetics, patients still experience nausea and/or vomiting during and after chemotherapy, especially with HEC. The efficacy of different antiemetics can vary according to various factors such as patient characteristics, the type of chemotherapy received as well as the site of cancer tumors. ${ }^{[12]}$ The addition of NK1 receptor antagonists to the antiemetic regimens has yielded a better armament for tackling CINV.

The most frequently used antiemetic regimen in our study was a combination of NK1 receptor antagonist, aprepitant along with 5-HT3 receptor antagonist, ondansetron and dexamethasone, followed by ondansetron with dexamethasone in all the three cycles of solid tumors.

The NK1 receptor antagonist prescribed in our study was a 3-day regimen of oral aprepitant. Along with this, patients were given premedication either with $8 \mathrm{mg}$ or $16 \mathrm{mg}$ each of ondansetron and dexamethasone, both given intravenously. A maintenance dose of oral ondansetron was also prescribed thrice a day for 5 days and to be taken as per the requirement as rescue medication. All doses prescribed were as per the treating physician's empirically based discretion.

We observed a deviation in the doses used for antiemetic drugs as compared to internationally used regimens. In a study done by Dranitsaris et al., patients were prescribed either a combination of ondansetron and dexamethasone added to aprepitant or only a regimen of ondansetron and dexamethasone. However, the regimen varied from our study as patients were premedicated with dexamethasone $12 \mathrm{mg}$ given intravenously and ondansetron $8 \mathrm{mg}$ given orally, repeated after 8 h. ${ }^{[13]} \mathrm{A}$ variation in the dosage regimen has reflected in the incomplete control of nausea and vomiting with the antiemetic regimens used in our study.

The patients reported anticipatory nausea as observed on the VAS in cycle 2 and cycle 3 at $0 \mathrm{~h}$. The anticipatory nausea was lesser in the aprepitant containing regimen as compared to the ondansetron and dexamethasone containing regimen.
In a study done by Molassiotis et al., they explored the incidence of anticipatory nausea in patients in successive chemotherapy cycles. They concluded that in patients receiving the second and third cycles of chemotherapy, there was a significant increase in patients presenting with anticipatory nausea, similar to our results. ${ }^{[14]}$

Profoundly symmetrical graphs are obtained when comparing VAS scores in the three cycles. There is a very minor difference in the intensity of nausea between the three cycles; thus, repeated exposure has not significantly reduced the susceptibility of the patients to experience nausea.

In our study, in the acute phase of cancer chemotherapy, the incidence of no emesis was better with the three-drug combination, containing aprepitant as compared to the two-drug regimen over the acute, delayed as well as overall phase. Similar results were observed across the second and third cycles of chemotherapy as well confirming the results of a study by Hilarius et al. in their investigation in a community hospital in daily practice. ${ }^{[15]}$ In their study, they observed that the control of emesis in the delayed phase did not vastly differ between the regimens which contained aprepitant as compared to the regimen without aprepitant. In contrast, we observed a marked difference in the delayed phase, an effect that may be explained by the longer action of aprepitant which persists beyond the acute phase.

Present guidelines for patients receiving HEC suggest the use of an NK 1 receptor antagonist along with premedication with ondansetron and dexamethasone for the adequate control of CINV, as well as additional prescription of olanzapine and dexamethasone on the subsequent days. ${ }^{[5]}$

The primary reason for inadequate prescription of the NK1 receptor antagonist was probably a lack of sensitization of physicians, as well as a lack of awareness of the latest recommendations. Due to inadequate knowledge of the advantages of olanzapine or dexamethasone, they were possibly not included in the antiemetic regimen of the patients in the maintenance dose as suggested by international guidelines. A suboptimal utilization of aprepitant as a prophylactic drug is most likely due to the socioeconomic constraints of the patients. The addition of aprepitant increases the cost incurred by the patient drastically as compared to a prescription of ondansetron-dexamethasone alone. In a resource-poor setting like India, a due consideration has to be made for the ability of the patients to afford the additional cost of aprepitant or other drugs of the same class. ${ }^{[16]}$

Some of our study limitations were inadequate sample size, as well as a possible bias due to the subjective nature of nausea. As our study sample consisted of only breast cancer patients, the assessment for other cancers may be inadequate. Further, a cost analysis can be performed to assess the economic impact of the control of CINV. 
This study can further be expanded to include different emetogenicity of chemotherapeutic regimens and different regimens of antiemetic drugs as well as can be investigated by the specific site of cancer to get a better impression of the extent of CINV.

\section{Conclusion}

For any patient being treated for cancer, the occurrence of CINV is a disturbing and immediate adverse effect that drastically effects the life of the patient. In our study, a statistically significant difference in VAS scores between the regimens was observed. In addition, we observed that with a combination of aprepitant, ondansetron, and dexamethasone, the control of CINV was better as compared to a regimen without aprepitant. Thus, more patients reported a better response, in terms of no emesis when prescribed aprepitant. Still, a lot needs to be done to achieve a complete cure in our setting. There is a constant need for constructing an evidence-based regimen that can be uniformly applied to optimize the efforts to control and treat this disturbing adverse effect of chemotherapy. Due consideration can be made to try and maximize the effectiveness of the antiemetic regimen to ensure patient compliance to chemotherapy.

\section{Acknowledgments}

The authors would like to sincerely acknowledge the contribution of Himalayan Institute of Medical Sciences and Cancer Research Institute, Himalayan Hospital Dehradun. The authors humbly thank the guidance provided by the faculty and staff of the Department of Pharmacology and Department of Medicine, HIMS, Dehradun. We would like to extend our gratitude to all colleagues for the support and encouragement.

\section{Financial support and sponsorship}

Nil.

\section{Conflicts of interest}

There are no conflicts of interest.

\section{References}

1. World Health Organization. Cancer Fact Sheet. WHO Media Centre. Available from: http://www.who.int/mediacentre/ factsheets/fs297/en/. [Last acessed on 2019 May 20].

2. World Health Organisation. Cancer Fact Sheet India 2018. International Agency for Research on Cancer. Available from: http:/gco.iarc.fr/today/data/factsheets/ populations/356-india-fact-sheets.pdf. [Last accessed on 2019 May 14].
3. Salihah N, Mazlan N, Lua PL. Chemotherapy-induced nausea and vomiting: exploring patients' subjective experience. J Multidiscip Healthc 2016;9:145-51.

4. Janelsins MC, Tejani MA, Kamen C, Peoples AR, Mustian KM, Morrow GR. Current pharmacotherapy for chemotherapy-induced nausea and vomiting in cancer patients. Expert Opin Pharmacother 2013;14:757-66.

5. Hesketh PJ, Kris MG, Basch E, Bohlke K, Barbour SY, Clark-Snow RA, et al. Antiemetics: American society of clinical oncology clinical practice guideline update. J Clin Oncol 2017;35:3240-61.

6. Navari RM. Treatment of breakthrough and refractory chemotherapy induced nausea and vomiting. Biomed Res Int 2015;2015:1-6.

7. Navari RM, editor. Management of Chemotherapy Induced Nausea and Vomiting: New Agents and New Uses of Current Agents.Switzerland: Springer; 2016.

8. Alfano CM, Leach CR, Smith TG, Miller KD, Alcaraz KI, Cannady RS, et al. Equitably improving outcomes for cancer survivors and supporting caregivers: A blueprint for care delivery, research, education, and policy. CA Cancer J Clin 2019;69:35-49.

9. Nurgali K, Jagoe RT, Abalo R. Editorial: Adverse effects of cancer chemotherapy: Anything new to improve tolerance and reduce sequelae? Front Pharmacol 2018;9:245.

10. Ko Y, Gwee YS, Huang YC, Chiang J, Chan A. Costs and length of stay of drug-related hospital admissions in cancer patients. Clin Ther 2014;36:588-92.

11. Paul EP, Behanan A, Eapen BA, James A, Sherief SH, Palanisamy MK, et al. A study on evaluation of anti-emetics in the prevention of chemotherapy induced nausea and vomiting in cancer patients in a Tertiary Care Hospital. Indian J Pharm Pract 2017;10:9-16.

12. Paul EP, Behanan A, Eapen BA, James A, Sherief SH, Palanisamy MK, et al. A study on evaluation of anti-emetics in the prevention of chemotherapy induced nausea and vomiting in cancer patients in a Tertiary Care Hospital. Indian J Pharm Pract 2017;10:9.

13. Dranitsaris G, Mazzarello S, Smith S, Vandermeer L, Bouganim N, Clemons M. Measuring the impact of guideline-based antiemetic therapy on nausea and vomiting control in breast cancer patients with multiple risk factors. Support Care Cancer 2016;24:1563-9.

14. Molassiotis A, Lee PH, Burke TA, Dicato M, Gascon P, Roila F, et al. Anticipatory nausea, risk factors, and its impact on chemotherapy-induced nausea and vomiting: Results from the pan European emesis registry study. J Pain Symptom Manage 2016;51:987-93.

15. Hilarius DL, Kloeg PH, van der Wall E, van den Heuvel JJ, Gundy CM, Aaronson NK. Chemotherapy-induced nausea and vomiting in daily clinical practice: A community hospital-based study. Support Care Cancer 2012;20:107-17.

16. Patil VM, Noronha V, Joshi A, Ramaswamy A, Gupta S, Sahu A, et al. Adherence to and implementation of ASCO antiemetic guidelines in routine practice in a tertiary cancer center in India. J Oncol Pract 2017;13:e574-81. 